\title{
Ideal quasi-Cauchy sequences
}

\author{
Huseyin Cakalli ${ }^{* *}$ and Bipan Hazarika
}

\author{
"Correspondence: \\ hcakalli@maltepe.edu.tr; \\ hcakalli@gmail.com \\ ${ }^{1}$ Department of Mathematics, \\ Maltepe University, Marmara Eğltim \\ Köyü, TR 34857, Maltepe, İstanbul, \\ Turkey \\ Full list of author information is \\ available at the end of the article
}

\begin{abstract}
An ideal / is a family of subsets of positive integers $\mathbf{N}$ which is closed under taking finite unions and subsets of its elements. A sequence $\left(x_{n}\right)$ of real numbers is said to be I-convergent to a real number $L$ if for each $\varepsilon>0$, the set $\left\{n:\left|x_{n}-L\right| \geq \varepsilon\right\}$ belongs to $I$. We introduce 1 -ward compactness of a subset of $\mathbf{R}$, the set of real numbers, and I-ward continuity of a real function in the senses that a subset $E$ of $\mathbf{R}$ is 1 -ward compact if any sequence $\left(x_{n}\right)$ of points in $E$ has an I-quasi-Cauchy subsequence, and a real function is I-ward continuous if it preserves I-quasi-Cauchy sequences where a sequence $\left(x_{n}\right)$ is called to be I-quasi-Cauchy when $\left(\Delta x_{n}\right)$ is I-convergent to 0 . We obtain results related to I-ward continuity, I-ward compactness, ward continuity, ward compactness, ordinary compactness, ordinary continuity, $\delta$-ward continuity, and slowly oscillating continuity.

MSC: Primary 40A35; secondary 40A05; 40G15; 26A15
\end{abstract}

Keywords: ideal; continuity; summability; compactness

\section{Introduction}

The concept of continuity and any concept involving continuity play a very important role not only in pure mathematics but also in other branches of sciences involving mathematics, especially in computer science, information theory, and biological science.

A subset $E$ of $\mathbf{R}$, the set of real numbers, is compact if any open covering of $E$ has a finite subcovering where $\mathbf{R}$ is the set of real numbers. This is equivalent to the statement that any sequence $\mathbf{x}=\left(x_{n}\right)$ of points in $E$ has a convergent subsequence whose limit is in $E$. A real function $f$ is continuous if and only if $\left(f\left(x_{n}\right)\right)$ is a convergent sequence whenever $\left(x_{n}\right)$ is. Regardless of limit, this is equivalent to the statement that $\left(f\left(x_{n}\right)\right)$ is Cauchy whenever $\left(x_{n}\right)$ is. Using the idea of continuity of a real function and the idea of compactness in terms of sequences, Çakallı [1] introduced the concept of ward continuity in the sense that a function $f$ is ward continuous if it preserves quasi-Cauchyness, i.e., $\left(f\left(x_{n}\right)\right)$ is a quasi-Cauchy sequence whenever $\left(x_{n}\right)$ is, and a subset $E$ of $\mathbf{R}$ is ward compact if any sequence $\mathbf{x}=\left(x_{n}\right)$ of points in $E$ has a quasi-Cauchy subsequence $\mathbf{z}=\left(z_{k}\right)=\left(x_{n_{k}}\right)$ of the sequence $\mathbf{x}$ where a sequence $\left(z_{k}\right)$ is called quasi-Cauchy if $\lim _{k \rightarrow \infty}\left(z_{k+1}-z_{k}\right)=0$ (see also [2], [3] and [4]). In [5] a real-valued function defined on a subset $E$ of $\mathbf{R}$ is called $\delta$-ward continuous if it preserves $\delta$-quasi Cauchy sequences where a sequence $\mathbf{x}=\left(x_{n}\right)$ is defined to be $\delta$-quasi Cauchy if the sequence $\left(\Delta x_{n}\right)$ is quasi-Cauchy. A subset $E$ of $\mathbf{R}$ is said to be $\delta$-ward compact if any sequence $\mathbf{x}=\left(x_{n}\right)$ of points in $E$ has a $\delta$-quasi-Cauchy subsequence $\mathbf{z}=\left(z_{k}\right)=\left(x_{n_{k}}\right)$ of the sequence $\mathbf{x}$.

A sequence $\left(x_{n}\right)$ of points in $\mathbf{R}$ is slowly oscillating if for any given $\varepsilon>0$, there exists a $\delta=$ $\delta(\varepsilon)>0$ and an $N=N(\varepsilon)$ such that $\left|x_{m}-x_{n}\right|<\varepsilon$ if $n \geq N(\varepsilon)$ and $n \leq m \leq(1+\delta) n$. A function 
defined on a subset $E$ of $\mathbf{R}$ is called slowly oscillating continuous if it preserves slowly oscillating sequences (see [6]). A function defined on a subset $E$ of $\mathbf{R}$ is called quasi-slowly oscillating continuous on $E$ if it preserves quasi-slowly oscillating sequences of points in $E$ where a sequence $\mathbf{x}=\left(x_{n}\right)$ is called quasi-slowly oscillating if $\left(\Delta x_{n}\right)=\left(x_{n+1}-x_{n}\right)$ is a slowly oscillating sequence [7].

The purpose of this paper is to investigate the concept of ideal ward compactness of a subset of $\mathbf{R}$ and the concept of ideal ward continuity of a real function which cannot be given by means of any summability matrix and to prove related theorems.

\section{Preliminaries}

First of all, some definitions and notation will be given in the following. Throughout this paper, $\mathbf{N}$ and $\mathbf{R}$ will denote the set of all positive integers and the set of all real numbers, respectively. We will use boldface letters $\mathbf{x}, \mathbf{y}, \mathbf{z}, \ldots$ for sequences $\mathbf{x}=\left(x_{n}\right), \mathbf{y}=\left(y_{n}\right), \mathbf{z}=\left(z_{n}\right)$, $\ldots$ of terms in R. $c$ and $S$ will denote the set of all convergent sequences and the set of all statistically convergent sequences of points in $\mathbf{R}$, respectively.

Following the idea given in a 1946 American Mathematical Monthly problem [8], a number of authors such as Posner [9], Iwinski [10], Srinivasan [11], Antoni [12], Antoni and Salat [13], Spigel and Krupnik [14] have studied $A$-continuity defined by a regular summability matrix $A$. Some authors, Öztürk [15], Savaş and Das [16], Borsik and Salat [17], have studied $A$-continuity for methods of almost convergence or for related methods.

The idea of statistical convergence was formerly given under the name 'almost convergence' by Zygmund in the first edition of his celebrated monograph published in Warsaw in 1935 [18]. The concept was formally introduced by Fast [19] and later was reintroduced by Schoenberg [20], and also independently by Buck [21]. Although statistical convergence was introduced over nearly the last seventy years, it has been an active area of research for twenty years. This concept has been applied in various areas such as number theory [22], measure theory [23], trigonometric series [18], summability theory [24], locally convex spaces [25], in the study of strong integral summability [26], turnpike theory [27-29], Banach spaces [30], metrizable topological groups [31], and topological spaces [32, 33]. It should be also mentioned that the notion of statistical convergence has been considered, in other contexts, by several people like R.A. Bernstein and Z. Frolik et al. The concept of statistical convergence is a generalization of the usual notion of convergence that, for real-valued sequences, parallels the usual theory of convergence. For a subset $M$ of $\mathbf{N}$, the asymptotic density of $M$ denoted by $\delta(M)$ is given by

$$
\delta(M)=\lim _{n \rightarrow \infty} \frac{1}{n}|\{k \leq n: k \in M\}|,
$$

if this limit exists where $|\{k \leq n: k \in M\}|$ denotes the cardinality of the set $\{k \leq n: k \in M\}$. A sequence $\left(x_{n}\right)$ is statistically convergent to $\ell$ if

$$
\delta\left(\left\{n:\left|x_{n}-\ell\right| \geq \epsilon\right\}\right)=0
$$

for every $\epsilon>0$. In this case, $\ell$ is called the statistical limit of $\mathbf{x}$. Schoenberg [20] studied some basic properties of statistical convergence and also studied the statistical convergence as a summability method. Fridy [34] gave characterizations of statistical convergence. Caserta, Maio, and Kočinac [35] studied statistical convergence in function spaces, while Caserta and Kočinac [36] investigated statistical exhaustiveness. 
By a lacunary sequence $\theta=\left(k_{r}\right)$, we mean an increasing sequence $\theta=\left(k_{r}\right)$ of positive integers such that $k_{0}=0$ and $h_{r}: k_{r}-k_{r-1} \rightarrow \infty$. The intervals determined by $\theta$ will be denoted by $I_{r}=\left(k_{r-1}, k_{r}\right]$, and the ratio $\frac{k_{r}}{k_{r-1}}$ will be abbreviated as $q_{r}$. In this paper, we assume that $\liminf _{r} q_{r}>1$. The notion of lacunary statistical convergence was introduced and studied by Fridy and Orhan in [37] and [38] (see also [39] and [40]). A sequence $\left(\alpha_{k}\right)$ of points in $\mathbf{R}$ is called lacunary statistically convergent to an element $\ell$ of $\mathbf{R}$ if

$$
\lim _{r \rightarrow \infty} \frac{1}{h_{r}}\left|\left\{k \in I_{r}:\left|\alpha_{k}-\ell\right| \geq \varepsilon\right\}\right|=0,
$$

for every positive real number $\varepsilon$. The condition assumed a few lines above ensures the regularity of the lacunary statistical sequential method.

The concept of $I$-convergence, which is a generalization of statistical convergence, was introduced by Kostyrko, S̆alàt, and Wilczyński [41] by using the ideal $I$ of subsets of $\mathbf{N}$ and further studied in [42-46], and [47]. The concept was also studied for double sequences in [48-51], and [52]. Although an ideal is defined as a hereditary and additive family of subsets of a non-empty arbitrary set $X$, here in our study, it suffices to take $I$ as a family of subsets of $\mathbf{N}$ such that $A \cup B \in I$ for each $A, B \in I$, and each subset of an element of $I$ is an element of $I$. A non-trivial ideal $I$ is called admissible if and only if $\{\{n\}: n \in \mathbf{N}\} \subset I$. A nontrivial ideal $I$ is maximal if there cannot exist any non-trivial ideal $J \neq I$ containing $I$ as a subset. Further details on ideals can be found in Kostyrko et al. (see [41]). Throughout this paper, we assume $I$ is a non-trivial admissible ideal in $\mathbf{N}$. Recall that a sequence $\mathbf{x}=\left(x_{n}\right)$ of points in $\mathbf{R}$ is said to be $I$-convergent to a real number $\ell$ if $\left\{n \in \mathbf{N}:\left|x_{n}-\ell\right| \geq \varepsilon\right\} \in I$ for every $\varepsilon>0$. In this case, we write $I-\lim x_{n}=\ell$. We say that a sequence $\left(x_{n}\right)$ of points in $\mathbf{R}$ is $I$-quasi-Cauchy if $I$ - $\lim \left(x_{n+1}-x_{n}\right)=0$. We see that $I$-convergence of a sequence $\left(x_{n}\right)$ implies $I$-quasi-Cauchyness of $\left(x_{n}\right)$. Throughout the paper, $I(\mathbf{R})$ and $\Delta I$ will denote the set of all $I$-convergent sequences and the set of all $I$-quasi-Cauchy sequences of points in $\mathbf{R}$, respectively.

If we take $I=I_{\text {fin }}=\{A \subseteq \mathbf{N}: A$ is a finite subset of $\mathbf{N}\}$, then $I_{\text {fin }}$ will be a non-trivial admissible ideal in $\mathbf{N}$, and the corresponding convergence will coincide with the usual convergence. If we take $I=I_{\delta}=\{A \subseteq \mathbf{N}: \delta(A)=0\}$, then $I_{\delta}$ will be a non-trivial admissible ideal of $\mathbf{N}$, and the corresponding convergence will coincide with the statistical convergence.

Connor and Grosse-Erdman [53] gave sequential definitions of continuity for real functions calling $G$-continuity instead of $A$-continuity. Their results cover the earlier works related to $A$-continuity where a method of sequential convergence, or briefly a method, is a linear function $G$ defined on a linear subspace of $s$, denoted by $c_{G}$, into $\mathbf{R}$. A sequence $\mathbf{x}=\left(x_{n}\right)$ is said to be $G$-convergent to $\ell$ if $\mathbf{x} \in c_{G}$ and $G(\mathbf{x})=\ell$. In particular, lim denotes the limit function $\lim \mathbf{x}=\lim _{n} x_{n}$ on the linear space $c$, and $s t$ - $\lim$ denotes the statistical limit function $s t$ - $\lim \mathbf{x}=s t-\lim _{n} x_{n}$ on the linear space $S$. Also $I$-lim denotes the $I$-limit function $I-\lim \mathbf{x}=I-\lim _{n} x_{n}$ on the linear space $I(\mathbf{R})$. A method $G$ is called regular if every convergent sequence $\mathbf{x}=\left(x_{n}\right)$ is $G$-convergent with $G(\mathbf{x})=\lim \mathbf{x}$. A method is called subsequential if whenever $\mathbf{x}$ is $G$-convergent with $G(\mathbf{x})=\ell$, then there is a subsequence $\left(x_{n_{k}}\right)$ of $\mathbf{x}$ with $\lim _{k} x_{n_{k}}=\ell$. Since the ordinary convergence implies ideal convergence, $I$ is a regular sequential method [54]. Recently, Cakalli studied new sequential definitions of compactness in $[55,56]$ and slowly oscillating compactness in $[6]$. 


\section{Ideal sequential compactness}

First, we recall the definition of $G$-sequentially compactness of a subset $E$ of $\mathbf{R}$. A subset $E$ of $\mathbf{R}$ is called $G$-sequentially compact if whenever $\left(x_{n}\right)$ is a sequence of points in $E$, there is subsequence $\mathbf{y}=\left(y_{k}\right)=\left(x_{n_{k}}\right)$ of $\left(x_{n}\right)$ such that $G(\mathbf{y})=\lim \mathbf{y}$ in $E$ (see [57]). For regular methods, any sequentially compact subset $E$ of $\mathbf{R}$ is also $G$-sequentially compact and the converse is not always true. For any regular subsequential method $G$, a subset $E$ of $\mathbf{R}$ is $G$-sequentially compact if and only if it is sequentially compact in the ordinary sense.

Although $I$-sequential compactness is a special case of $G$-sequential compactness when $G=\lim$, we state the definition of $I$-sequential compactness of a subset $E$ of $\mathbf{R}$ as follows.

Definition 1 A subset $E$ of $\mathbf{R}$ is called $I$-sequentially compact if whenever $\left(x_{n}\right)$ is a sequence of points in $E$, there is an $I$-convergent subsequence $\mathbf{y}=\left(y_{k}\right)=\left(x_{n_{k}}\right)$ of $\left(x_{n}\right)$ such that $I$ - $\lim \mathbf{y}$ is in $E$.

Lemma 1 [41] Sequential method I is regular, i.e., if $\lim x_{n}=\ell$, then $I-\lim x_{n}=\ell$.

Lemma 2 ([58], Proposition 3.2) Any I-convergent sequence of points in $\mathbf{R}$ with an I-limit $\ell$ has a convergent subsequence with the same limit $\ell$ in the ordinary sense.

We have the following result which states that any non-trivial admissible ideal $I$ is a regular subsequential sequential method.

Theorem 1 The sequential method I is regular and subsequential.

Proof Regularity of $I$ follows from Lemma 1, and subsequentiality of $I$ follows from Lemma 2.

Theorem 2 ([55], Corollary 3) A subset of $\mathbf{R}$ is sequentially compact if and only if it is I-sequentially compact.

Although $I$-sequential continuity is a special case of $G$-sequential continuity when $G=$ lim, we state the definition of $I$-sequential continuity of a function defined on a subset $E$ of $\mathbf{R}$ as follows.

Definition 2 ([54], Definition 2) A function $f: E \rightarrow \mathbf{R}$ is $I$-sequentially continuous at a point $x_{0}$ if, given a sequence $\left(x_{n}\right)$ of points in $E, I$ - $\lim \mathbf{x}=x_{0}$ implies that $I$ - $\lim f(\mathbf{x})=f\left(x_{0}\right)$.

Theorem 3 Any I-sequentially continuous function at a point $x_{0}$ is continuous at $x_{0}$ in the ordinary sense.

Proof Although there is a proof in [54], we give a different proof for completeness. Let $f$ be any $I$-sequentially continuous function at a point $x_{0}$. Since any proper admissible ideal is a regular subsequential method by Theorem 1 , it follows from [57], Theorem 13, that $f$ is continuous in the ordinary sense.

Theorem 4 ([54], Theorem 2.2) Any continuous function at a point $x_{0}$ is I-sequentially continuous at $x_{0}$. 
Combining Theorem 3 and Theorem 4 we have the following corollary.

Corollary 1 A function is I-sequentially continuous at a point $x_{0}$ if and only if it is continuous at $x_{0}$.

As statistical limit is an $I$-sequential method, we get ([56], Theorem 2).

Corollary 2 A function is statistically continuous at a point $x_{0}$ if and only if it is continuous at $x_{0}$ in the ordinary sense.

As lacunary statistical limit is an $I$-sequential method, we get ([56], Theorem 5).

Corollary 3 A function is lacunarily statistically continuous at a point $x_{0}$ if and only if it is continuous at $x_{0}$ in the ordinary sense.

Corollary 4 For any regular subsequential method G, a function is G-sequentially continuous at a point $x_{0}$, then it is I-sequentially continuous at $x_{0}$.

Proof The proof follows from [57], Theorem 13.

Corollary 5 Any ward continuous function on a subset $E$ of $\mathbf{R}$ is I-sequentially continuous on $E$.

Theorem 5 If a function is slowly oscillating continuous on a subset $E$ of $\mathbf{R}$, then it is Isequentially continuous on $E$.

Proof Let $f$ be any slowly oscillating continuous function on $E$. It follows from [6], Theorem 2.1, that $f$ is continuous. By Theorem 4 , we see that $f$ is $I$-sequentially continuous on $E$. This completes the proof.

Theorem 6 If a function is $\delta$-ward continuous on a subset $E$ of $\mathbf{R}$, then it is I-sequentially continuous on $E$.

Proof Let $f$ be any $\delta$-ward continuous function on $E$. It follows from [5], Corollary 2, that $f$ is continuous. By Theorem 4, we obtain that $f$ is $I$-sequentially continuous on $E$. This completes the proof.

Corollary 6 If a function is quasi-slowly oscillating continuous on a subset $E$ of $\mathbf{R}$, then it is I-sequentially continuous on $E$.

Proof Let $f$ be any quasi-slowly oscillating continuous function on $E$. It follows from [7], Theorem 3.2, that $f$ is continuous. By Theorem 4 , we deduce that $f$ is $I$-sequentially continuous on $E$. This completes the proof.

\section{Ideal ward continuity}

We say that a sequence $\mathbf{x}=\left(x_{n}\right)$ is $I$-ward convergent to a number $\ell$ if $I$ - $\lim _{n \rightarrow \infty} \Delta x_{n}=\ell$. For the special case $\ell=0$, we say that $\mathbf{x}$ is ideal quasi-Cauchy or $I$-quasi-Cauchy.

Now, we give the definition of $I$-ward compactness of a subset of $\mathbf{R}$. 
Definition 3 A subset $E$ of $\mathbf{R}$ is called $I$-ward compact if whenever $\mathbf{x}=\left(x_{n}\right)$ is a sequence of points in $E$, there is an $I$-quasi-Cauchy subsequence of $\mathbf{x}$.

We note that this definition of $I$-ward compactness cannot be obtained by any Gsequential compactness, i.e., by any summability matrix $A$, even by the summability matrix $A=\left(a_{n k}\right)$ defined by $a_{n k}=-1$ if $k=n$ and $a_{k n}=1$ if $k=n+1$ and

$$
G(x)=I-\lim A \mathbf{x}=I-\lim _{k \rightarrow \infty} \sum_{n=1}^{\infty} a_{k n} x_{n}=I-\lim _{k \rightarrow \infty} \Delta x_{k} .
$$

Despite the fact that $G$-sequential compact subsets of $\mathbf{R}$ should include the singleton set $\{0\}, I$-ward compact subsets of $\mathbf{R}$ do not have to include the singleton $\{0\}$.

Firstly, we note that any finite subset of $\mathbf{R}$ is $I$-ward compact, the union of two $I$-ward compact subsets of $\mathbf{R}$ is $I$-ward compact, and the intersection of any $I$-ward compact subsets of $\mathbf{R}$ is $I$-ward compact. Furthermore, any subset of an $I$-ward compact set is $I$-ward compact, and any bounded subset of $\mathbf{R}$ is $I$-ward compact. Any compact subset of $\mathbf{R}$ is also $I$-ward compact, and the set $\mathbf{N}$ is not $I$-ward compact. We note that any slowly oscillating compact subset of $\mathbf{R}$ is $I$-ward compact (see [6] for the definition of slowly oscillating compactness). These observations suggest that we have the following result.

Theorem 7 A subset $E$ of $\mathbf{R}$ is ward compact if and only if it is I-ward compact.

Proof Let us suppose first that $E$ is ward compact. It follows from [2], Lemma 2, that $E$ is bounded. Then for any sequence $\left(x_{n}\right)$, there exists a convergent subsequence $\left(x_{n_{k}}\right)$ of $\left(x_{n}\right)$ whose limit may be in $E$ or not. Then the sequence $\left(\Delta x_{n_{k}}\right)$ is a null sequence. Since $I$ is a regular method, $\left(\Delta x_{n_{k}}\right)$ is $I$-convergent to 0 , so it is $I$-quasi-Cauchy. Thus, $E$ is $I$-ward compact.

Now, to prove the converse, suppose that $E$ is $I$-ward compact. Take any sequence $\left(x_{n}\right)$ of points in $E$. Then there exists an $I$-quasi-Cauchy subsequence $\left(x_{n_{k}}\right)$ of $\left(x_{n}\right)$. Since $I$ is subsequential, there exists a convergent subsequence $\left(x_{n_{k_{m}}}\right)$ of $\left(x_{n_{k}}\right)$. The sequence $\left(x_{n_{k_{m}}}\right)$ is a quasi-Cauchy subsequence of the sequence $\left(x_{n}\right)$. Thus, $E$ is ward compact. This completes the proof of the theorem.

Theorem $\mathbf{8}$ A subset $E$ of $\mathbf{R}$ is bounded if and only if it is I-ward compact.

Proof Using an idea in the proof of [2], Lemma 2, and the preceding theorem, the proof can be obtained easily, so it is omitted.

Now, we give the definition of $I$-ward continuity of a real function.

Definition 4 A function $f$ is called $I$-ward continuous on a subset $E$ of $\mathbf{R}$ if $I$ - $\lim _{n \rightarrow \infty} \Delta f\left(x_{n}\right)=0$ whenever $I-\lim _{n \rightarrow \infty} \Delta x_{n}=0$ for a sequence $\mathbf{x}=\left(x_{n}\right)$ of terms in $E$.

We note that this definition of continuity cannot be obtained by any $A$-continuity, i.e., by any summability matrix $A$, even by the summability matrix $A=\left(a_{n k}\right)$ defined by (1). However, for this special summability matrix $A$, if $A$-continuity of $f$ at the point 0 implies $I$-ward continuity of $f$, then $f(0)=0$; and if $I$-ward continuity of $f$ implies $A$-continuity of $f$ at the point 0 , then $f(0)=0$. 
We note that the sum of two $I$-ward continuous functions is $I$-ward continuous, but the product of two $I$-ward continuous functions need not be $I$-ward continuous as it can be seen by considering a product of the $I$-ward continuous function $f(x)=x$ with itself.

In connection with $I$-quasi-Cauchy sequences and $I$-convergent sequences, the problem arises to investigate the following types of 'continuity' of functions on $\mathbf{R}$ :

$(\delta i): \quad\left(x_{n}\right) \in \Delta I \Rightarrow\left(f\left(x_{n}\right)\right) \in \Delta I$,

(8ic): $\left(x_{n}\right) \in \Delta I \Rightarrow\left(f\left(x_{n}\right)\right) \in c$,

(c): $\quad\left(x_{n}\right) \in c \Rightarrow\left(f\left(x_{n}\right)\right) \in c$,

$(c \delta i):\left(x_{n}\right) \in c \Rightarrow\left(f\left(x_{n}\right)\right) \in \Delta I$,

(i): $\quad\left(x_{n}\right) \in I(\mathbf{R}) \Rightarrow\left(f\left(x_{n}\right)\right) \in I(\mathbf{R})$.

We see that $(\delta i)$ is $I$-ward continuity of $f,(i)$ is $I$-continuity of $f$ and $(c)$ states the ordinary continuity of $f$. It is easy to see that $(\delta i c)$ implies $(\delta i)$ and $(\delta i)$ does not imply $(\delta i c)$; $(\delta i)$ implies $(c \delta i)$ and $(c \delta i)$ does not imply $(\delta i) ;(\delta i c)$ implies $(c)$ and $(c)$ does not imply $(\delta i c)$; and $(c)$ is equivalent to $(c \delta i)$.

Now, we give the implication $(\delta i)$ implies $(i)$, i.e., any $I$-ward continuous function is $I$ sequentially continuous.

Theorem 9 Iff is I-ward continuous on a subset $E$ of $\mathbf{R}$, then it is I-sequentially continuous on $E$.

Proof Although the following proof is similar to that of [59], Theorem 1, and that of [7], Theorem 3.2, we give it for completeness. Suppose that $f$ is an $I$-ward continuous function on a subset $E$ of $\mathbf{R}$. Let $\left(x_{n}\right)$ be an $I$-quasi-Cauchy sequence of points in $E$. Then the sequence

$$
\left(x_{1}, x_{0}, x_{2}, x_{0}, x_{3}, x_{0}, \ldots, x_{n-1}, x_{0}, x_{n}, x_{0}, \ldots\right)
$$

is an $I$-quasi-Cauchy sequence. Since $f$ is $I$-ward continuous, the sequence

$$
\left(y_{n}\right)=\left(f\left(x_{1}\right), f\left(x_{0}\right), f\left(x_{2}\right), f\left(x_{0}\right), \ldots, f\left(x_{n}\right), f\left(x_{0}\right), \ldots\right)
$$

is an $I$-quasi-Cauchy sequence. Therefore, $I-\lim _{n \rightarrow \infty} \Delta y_{n}=0$. Hence, $I-\lim _{n \rightarrow \infty}\left[f\left(x_{n}\right)-\right.$ $\left.f\left(x_{0}\right)\right]=0$. It follows that the sequence $\left(f\left(x_{n}\right)\right) I$-converges to $f\left(x_{0}\right)$. This completes the proof of the theorem.

The converse is not always true for the function $f(x)=x^{2}$ is an example since $I-\lim _{n \rightarrow \infty} \Delta x_{n}=0$ for the sequence $\left(x_{n}\right)=(\sqrt{n})$. But $I-\lim _{n \rightarrow \infty} \Delta f\left(x_{n}\right) \neq 0$, because $(f(\sqrt{n}))=(n)$.

Theorem 10 Iff is I-ward continuous on a subset $E$ of $\mathbf{R}$, then it is continuous on $E$ in the ordinary sense.

Proof Let $f$ be an $I$-ward continuous function on $E$. By Theorem 9, $f$ is $I$-sequentially continuous on $E$. It follows from Theorem 3 that $f$ is continuous on $E$ in the ordinary sense. Thus, the proof is completed. 
Theorem 11 An I-ward continuous image of any I-ward compact subset of $\mathbf{R}$ is I-ward compact.

Proof Suppose that $f$ is an $I$-ward continuous function on a subset $E$ of $\mathbf{R}$, and $E$ is an $I$-ward compact subset of $\mathbf{R}$. Let $\mathbf{y}=\left(y_{n}\right)$ be a sequence of points in $f(E)$. Write $y_{n}=f\left(x_{n}\right)$, where $x_{n} \in E$ for each $n \in \mathbf{N}$. $I$-ward compactness of $E$ implies that there is an $I$-quasiCauchy subsequence $\mathbf{z}=\left(z_{k}\right)=\left(x_{n_{k}}\right)$ of $\left(x_{n}\right)$. As $f$ is $I$-ward continuous, $\left(f\left(z_{k}\right)\right)$ is an $I$ quasi-Cauchy subsequence of $\mathbf{y}$. Thus, $f(E)$ is $I$-ward compact. This completes the proof of the theorem.

Corollary 7 An I-ward continuous image of any compact subset of $\mathbf{R}$ is compact.

Proof The proof of this theorem follows from Theorem 3.

Corollary 8 An I-ward continuous image of any bounded subset of $\mathbf{R}$ is bounded.

Proof The proof follows from Theorem 8 and Theorem 10.

Corollary 9 An I-ward continuous image of a G-sequentially compact subset of $\mathbf{R}$ is Gsequentially compact for any regular subsequential method $G$.

It is a well-known result that a uniform limit of a sequence of continuous functions is continuous. It is true for slowly oscillating continuous functions ([56], Theorem 12), and quasi-slowly oscillating continuous functions ([7], Theorem 3.5), (see also [59], Theorem 5). This is also true in the case of $I$-ward continuity, i.e., a uniform limit of a sequence of $I$-ward continuous functions is $I$-ward continuous.

Theorem 12 If $\left(f_{n}\right)$ is a sequence of I-ward continuous functions defined on a subset $E$ of $\mathbf{R}$, and $\left(f_{n}\right)$ is uniformly convergent to a function $f$, then $f$ is I-ward continuous on $E$.

Proof Let $\varepsilon>0$ and $\left(x_{n}\right)$ be a sequence of points in $E$ such that $I-\lim _{n \rightarrow \infty} \Delta x_{n}=0$. By the uniform convergence of $\left(f_{n}\right)$, there exists a positive integer $N$ such that $\left|f_{n}(x)-f(x)\right|<\frac{\varepsilon}{3}$ for all $x \in E$ whenever $n \geq N$. By the definition of ideal convergence, for all $x \in E$, we have

$$
\left\{n \in \mathbf{N}:\left|f_{n}(x)-f(x)\right| \geq \frac{\varepsilon}{3}\right\} \in I
$$

As $f_{N}$ is $I$-ward continuous on $E$, we have

$$
\left\{n \in \mathbf{N}:\left|f_{N}\left(x_{n+1}\right)-f_{N}\left(x_{n}\right)\right| \geq \frac{\varepsilon}{3}\right\} \in I .
$$

On the other hand, we have

$$
\begin{aligned}
& \left\{n \in \mathbf{N}:\left|f\left(x_{n+1}\right)-f\left(x_{n}\right)\right| \geq \varepsilon\right\} \\
& \subseteq\left\{\left\{n \in \mathbf{N}:\left|f\left(x_{n+1}\right)-f_{N}\left(x_{n+1}\right)\right| \geq \frac{\varepsilon}{3}\right\}\right. \\
& \left.\quad \cup\left\{n \in \mathbf{N}:\left|f_{N}\left(x_{n+1}\right)-f_{N}\left(x_{n}\right)\right| \geq \frac{\varepsilon}{3}\right\} \cup\left\{n \in \mathbf{N}:\left|f_{N}\left(x_{n}\right)-f\left(x_{n}\right)\right| \geq \frac{\varepsilon}{3}\right\}\right\} .
\end{aligned}
$$


Since $I$ is an admissible ideal, the right-hand side of the relation (3) belongs to $I$, we have

$$
\left\{n \in \mathbf{N}:\left|f\left(x_{n+1}\right)-f\left(x_{n}\right)\right| \geq \varepsilon\right\} \in I .
$$

This completes the proof of the theorem.

Theorem 13 The set of all I-ward continuous functions on a subset $E$ of $\mathbf{R}$ is a closed subset of the set of all continuous functions on $E$, i.e., $\overline{\Delta \operatorname{iwc}(E)}=\Delta \mathrm{iwc}(E)$, where $\Delta \operatorname{iwc}(E)$ is the set of all I-ward continuous functions on $E, \overline{\Delta \mathrm{iwc}(E)}$ denotes the set of all cluster points of $\Delta \operatorname{iwc}(E)$.

Proof Let $f$ be an element in $\overline{\Delta \operatorname{iwc}(E)}$. Then there exists a sequence $\left(f_{n}\right)$ of points in $\Delta \mathrm{iwc}(E)$ such that $\lim _{n \rightarrow \infty} f_{n}=f$. To show that $f$ is $I$-ward continuous, consider an $I$ quasi-sequence $\left(x_{n}\right)$ of points in $E$. Since $\left(f_{n}\right)$ converges to $f$, there exists a positive integer $N$ such that for all $x \in E$ and for all $n \geq N,\left|f_{n}(x)-f(x)\right|<\frac{\varepsilon}{3}$. By the definition of an ideal for all $x \in E$, we have

$$
\left\{n \in \mathbf{N}:\left|f_{n}(x)-f(x)\right| \geq \frac{\varepsilon}{3}\right\} \in I
$$

As $f_{N}$ is $I$-ward continuous on $E$, we have

$$
\left\{n \in \mathbf{N}:\left|f_{N}\left(x_{n+1}\right)-f_{N}\left(x_{n}\right)\right| \geq \frac{\varepsilon}{3}\right\} \in I .
$$

On the other hand, we have

$$
\begin{aligned}
& \left\{n \in \mathbf{N}:\left|f\left(x_{n+1}\right)-f\left(x_{n}\right)\right| \geq \varepsilon\right\} \\
& \subseteq\left\{\left\{n \in \mathbf{N}:\left|f\left(x_{n+1}\right)-f_{N}\left(x_{n+1}\right)\right| \geq \frac{\varepsilon}{3}\right\}\right. \\
& \left.\quad \cup\left\{n \in \mathbf{N}:\left|f_{N}\left(x_{n+1}\right)-f_{N}\left(x_{n}\right)\right| \geq \frac{\varepsilon}{3}\right\} \cup\left\{n \in \mathbf{N}:\left|f_{N}\left(x_{n}\right)-f\left(x_{n}\right)\right| \geq \frac{\varepsilon}{3}\right\}\right\} .
\end{aligned}
$$

Since $I$ is an admissible ideal, the right-hand side of the relation (3) belongs to $I$, we have

$$
\left\{n \in \mathbf{N}:\left|f\left(x_{n+1}\right)-f\left(x_{n}\right)\right| \geq \frac{\varepsilon}{3}\right\} \in I
$$

This completes the proof of the theorem.

We note that [59], Theorem 6, [56], Theorem 10, and [7], Theorem 2.2, Theorem 3.9, supply some other closed subsets of the set of all continuous functions.

Corollary 10 The set of all I-ward continuous functions on a subset $E$ of $\mathbf{R}$ is a complete subspace of the space of all continuous functions on $E$.

Proof The proof follows from the preceding theorem. 
In this paper, two new concepts, namely the concept of $I$-ward continuity of a real function and the concept of $I$-ward compactness of a subset of $\mathbf{R}$, were introduced and investigated. In this investigation, we have obtained theorems related to $I$-ward continuity, $I$-ward compactness, compactness, sequential continuity, and uniform continuity. We also introduced and studied some other continuities involving $I$-quasi-Cauchy sequences, statistical sequences, and convergent sequences of points in $\mathbf{R}$. The present work also contains a generalization of results of the paper [1], and some results in [2] and [4].

\section{Competing interests}

The authors declare that they have no competing interests.

\section{Authors' contributions}

$\mathrm{BH}$ drafted the manuscript. $\mathrm{HC}$ checked and organized the manuscript to be its final form and make the revision as the corresponding author.

\section{Author details}

'Department of Mathematics, Maltepe University, Marmara Eğlitim Köyü, TR 34857, Maltepe, İstanbul, Turkey.

${ }^{2}$ Department of Mathematics, Rajiv Gandhi University, Doimukh, Arunachal Pradesh, India.

\section{Acknowledgements}

The authors would like to thank the referees for a careful reading and several constructive comments that have improved the presentation of the results.

Received: 20 July 2012 Accepted: 28 September 2012 Published: 17 October 2012

\section{References}

1. Çakallı, H: Forward continuity. J. Comput. Anal. Appl. 13(2), 225-230 (2011) MR 2012c:26004

2. Çakallı, H: Statistical ward continuity. Appl. Math. Lett. 24(10), 1724-1728 (2011) MR 2012f:40020

3. Burton, D, Coleman, J: Quasi-Cauchy sequences. Am. Math. Mon. 117(4), 328-333 (2010) MR 2011c:40004

4. Çakallı, H: Statistical-quasi-Cauchy sequences. Math. Comput. Model. 54(5-6), 1620-1624 (2011) MR $2012 f: 40006$

5. Çakallı, H: Delta quasi-Cauchy sequences. Math. Comput. Model. 53, 397-401 (2011) MR 2011m:26004

6. Çakallı, H: Slowly oscillating continuity. Abstr. Appl. Anal. 2008, Article ID 485706 (2008). doi:10.1155/2008/485706 MR 2009b:26004

7. Dik, M, Canak, I: New types of continuities. Abstr. Appl. Anal. 2010, Article ID 258980 (2010). doi:10.1155/2010/258980 MR 2011c:26005, MR 2011c:26005

8. Buck, RC: Solution of problem 4216. Am. Math. Mon. 55, 36 (1948) MR 15: 26874

9. Posner, EC: Summability preserving functions. Proc. Am. Math. Soc. 12, 73-76 (1961) MR 2212327

10. Iwinski, TB: Some remarks on Toeplitz methods and continuity. Ann. Soc. Math. Pol., 1 Comment. Math. 17, 37-43 (1972) MR 48759

11. Srinivasan, VK: An equivalent condition for the continuity of a function. Tex. J. Sci. 32, 176-177 (1980) MR $81 f: 26001$

12. Antoni, J: On the A-continuity of real functions II. Math. Slovaca 36(3), 283-287 (1986) MR 88a:26001

13. Antoni, J, Salat, T: On the A-continuity of real functions. Acta Math. Univ. Comen. 39, 159-164 (1980) MR 82h:26004

14. Spigel, E, Krupnik, N: On the A-continuity of real functions. J. Anal. 2, 145-155 (1994) MR 95h:26004

15. Öztürk, E: On almost-continuity and almost A-continuity of real functions. Commun. Fac. Sci. Univ. Ank. Ser. A1 Math. Stat. 32, 25-30 (1983) MR 86h:26003

16. Savaș, E, Das, G: On the A-continuity of real functions. Istanb. Üniv. Fen Fak. Mat. Derg. 53, 61-66 (1994) MR 97m:26004

17. Borsik, J, Salát, T: On F-continuity of real functions. Tatra Mt. Math. Publ. 2, 37-42 (1993) MR 94m:26006

18. Zygmund, A: Trigonometric Series. I, II. 3rd edn. Cambridge University Press, Cambridge (2002). With a foreword by Robert A. Fefferman. Cambridge Mathematical Library. MR 2004h:01041

19. Fast, H: Sur la convergence statistique. Colloq. Math. 2, 241-244 (1951) MR 14:29c

20. Schoenberg, IJ: The integrability of certain functions and related summability methods. Am. Math. Mon. 66, 361-375 (1959) MR 21:3696

21. Buck, RC: Generalized asymptotic density. Am. J. Math. 75, 335-346 (1953) MR $14854 f$

22. Erdos, P, Tenenbaum, G: Sur les densités de certaines suites d'entiers. Proc. Lond. Math. Soc. 59(3), 417-438 (1989) MR 90h:11087

23. Miller, HI: A measure theoretical subsequence characterization of statistical convergence. Trans. Am. Math. Soc 347(5), 1811-1819 (1995) MR 95h:40010

24. Freedman, AR, Sember, JJ: Densities and summability. Pac. J. Math. 95(2), 293-305 (1981) MR 82m:10081

25. Maddox, IJ: Statistical convergence in a locally convex space. Math. Proc. Camb. Philos. Soc. 104(1), 141-145 (1988) MR 89k:40012

26. Connor, J, Swardson, MA: Strong integral summability and the Stone-Cech compactification of the half-line. Pac. J. Math. 157(2), 201-224 (1993) MR 94f:40007

27. Makarov, VL, Levin, MJ, Rubinov, AM: Mathematical Economic Theory: Pure and Mixed Types of Economic Mechanisms. Advanced Textbooks in Economics, vol. 33. North-Holland, Amsterdam (1995)

28. Mckenzie, LW: Turnpike theory. Econometrica 44(5), 841-865 (1976) MR 56:17735

29. Pehlivan, S, Mamedov, MA: Statistical cluster points and turnpike. Optimization 48(1), 93-106 (2000) MR 2001b:49008

30. Connor, J, Ganichev, M, Kadets, V: A characterization of Banach spaces with separable duals via weak statistical convergence. J. Math. Anal. Appl. 244(1), 251-261 (2000) MR 2000m:46042 
31. Çakallı, H: Lacunary statistical convergence in topological groups. Indian J. Pure Appl. Math. 26(2), 113-119 (1995) MR 95m:40016

32. Di Maio, G, Kočinac, LDR: Statistical convergence in topology. Topol. Appl. 156, 28-45 (2008) MR 2009k:54009

33. Çakallı, H, Khan, MK: Summability in topological spaces. Appl. Math. Lett. 24(3), 348-352 (2011) MR 2011 m:40026

34. Fridy, JA: On statistical convergence. Analysis 5, 301-313 (1985) MR 87b:40001

35. Caserta, A, Di Maio, G, Kočinac, LDR: Statistical convergence in function spaces. Abstr. Appl. Anal. 2011, Article ID 420419 (2011). doi:10.1155/2011/420419 MR 2012k:40003

36. Caserta, A, Kočinac, LDR: On statistical exhaustiveness. Appl. Math. Lett. 25(10), 1447-1451 (2012). doi:10.1016/j.aml.2011.12.022

37. Fridy, JA, Orhan, C: Lacunary statistical convergence. Pac. J. Math. 160(1), 43-51 (1993) MR 94j:40014

38. Fridy, JA, Orhan, C: Lacunary statistical summability. J. Math. Anal. Appl. 173(2), 497-504 (1993) MR $95 f: 40004$

39. Freedman, AR, Sember, JJ, Raphael, M: Some Cesaro-type summability spaces. Proc. Lond. Math. Soc. 3(37), 508-520 (1978) MR 80c:40007

40. Karakaya, V: Some geometric properties of sequence spaces involving lacunary sequence. J. Inequal. Appl. 2007, Art. ID 81028 (2007) MR 2009k:46037

41. Kostyrko, P, Šalàt, T, Wilczyński, W: I-convergence. Real Anal. Exch. 26(2), 669-686 (2000-2001) MR 2002e:54002

42. Mursaleen, M, Alotaibi, A: On I-convergence in random 2-normed spaces. Math. Slovaca 61(6), 933-940 (2011) MR $2012 \mathrm{k}: 40006$

43. Sahiner, A, Gurdal, M, Saltan, S, Gunawan, H: Ideal convergence in 2-normed spaces. Taiwan. J. Math. 11, 1477-1484 (2007) MR 2008j:46006

44. Savas, E: On some new sequence spaces in 2-normed spaces using ideal convergence and an Orlicz function. J. Inequal. Appl. 2010, Art. ID 482392 (2010) MR $2011 \mathrm{k}: 46003$

45. Mursaleen, M, Mohiuddine, SA: On ideal convergence in probabilistic normed spaces. Math. Slovaca 62, 49-62 (2012)

46. Mursaleen, M, Abdullah, A, Mohammed, AA: I-Summability and I-approximation through invariant mean. J. Comput. Anal. Appl. 14(6), 1049-1058 (2012)

47. Komisarski, A: Pointwise $/$-convergence and $l^{*}$-convergence in measure of sequences of functions. J. Math. Anal. Appl. 340, 770-779 (2008) MR 2009j:28010

48. Kumar, V: On / and $l$ "-convergence of double sequences. Math. Commun. 12, 171-181 (2007) MR 2009c:40007

49. Mursaleen, M, Mohiuddine, SA: On ideal convergence of double sequences in probabilistic normed spaces. Math. Rep. 12(62)(4), 359-371 (2010) MR 2012a:40007

50. Mursaleen, $\mathrm{M}$, Mohiuddine, $\mathrm{SA}$, Edely, $\mathrm{OHH}$ : On the ideal convergence of double sequences in intuitionistic fuzzy normed spaces. Comput. Math. Appl. 59(2), 603-611 (2010) MR 2010k:40004

51. Das, P, Kostyrko, P, Wilczynski, W, Malik, P: / and I"-convergence of double sequences. Math. Slovaca 58, 605-620 (2008) MR 2010e:40007

52. Savas, E: On generalized A-difference strongly summable sequence spaces defined by ideal convergence on a real n-normed space. J. Inequal. Appl. 2012, 87 (2012). doi:10.1186/1029-242X-2012-87

53. Connor, J, Grosse-Erdmann, KG: Sequential definitions of continuity for real functions. Rocky Mt. J. Math. 33(1), 93-121 (2003) MR 2004e:26004

54. Sleziak, M: I-continuity in topological spaces. Acta Mathematica, Faculty of Natural Sciences, Constantine the Philosopher University Nitra 6, 115-122 (2003)

55. Çakallı, H: Sequential definitions of compactness. Appl. Math. Lett. 21(6), 594-598 (2008) MR 2009b:40005

56. Cakallı, H: New kinds of continuities. Comput. Math. Appl. 61(4), 960-965 (2011) MR 2011j:54008

57. Çakallı, H: On G-continuity. Comput. Math. Appl. 61(2), 313-318 (2011) MR 2011 m:40002

58. Salát, T, Tripathy, BC, Zimon, M: On some properties of I-convergence. Tatra Mt. Math. Publ. 28, 279-286 (2004) MR 2005h:40004

59. Çakallı, H: On $\Delta$-quasi-slowly oscillating sequences. Comput. Math. Appl. 62(9), 3567-3574 (2011)

doi:10.1186/1029-242X-2012-234

Cite this article as: Cakalli and Hazarika: Ideal quasi-Cauchy sequences. Journal of Inequalities and Applications 2012 2012:234.

\section{Submit your manuscript to a SpringerOpen ${ }^{\circ}$ journal and benefit from:}

- Convenient online submission

- Rigorous peer review

- Immediate publication on acceptance

- Open access: articles freely available online

- High visibility within the field

- Retaining the copyright to your article

Submit your next manuscript at $>$ springeropen.com 